\title{
Innate Immunity to Enteric Hepatitis Viruses
}

\author{
Zongdi Feng ${ }^{1}$ and Stanley M. Lemon ${ }^{2}$ \\ ${ }^{1}$ Center for Vaccines and Immunity, The Research Institute at Nationwide Children's Hospital, The Ohio State \\ University College of Medicine, Columbus, Ohio 43205 \\ ${ }^{2}$ Departments of Medicine and Microbiology \& Immunology, Lineberger Comprehensive Cancer Center, \\ The University of North Carolina, Chapel Hill, North Carolina 27599 \\ Correspondence: zongdi.feng@nationwidechildrens.org; smlemon@med.unc.edu
}

\begin{abstract}
Although hepatitis A virus (HAV) and hepatitis E virus (HEV) are both positive-strand RNA viruses that replicate in the cytoplasm of hepatocytes, there are important differences in the ways they induce and counteract host innate immune responses. HAV is remarkably stealthy because of its ability to evade and disrupt innate signaling pathways that lead to interferon production. In contrast, HEV does not block interferon production. Instead, it persists in the presence of an interferon response. These differences may provide insight into HEV persistence in immunocompromised patients, an emerging health problem in developed countries.
\end{abstract}

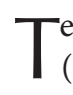
extbooks often consider hepatitis A virus (HAV) and hepatitis E virus (HEV) together because their modes of transmission and clinical presentations are relatively similar. Historically, both viruses have been thought to cause only acute disease, diminishing the interest in studying them, in contrast to hepatitis B virus (HBV) and hepatitis $\mathrm{C}$ virus (HCV) that persist and cause chronic hepatitis. As a result, the immune responses generated by HAV and HEV and the pathogenesis of both infections remain relatively poorly understood. However, recent advances in molecular techniques and animal models have provided new insight into these viruses and show that the host responses to these two agents are quite different. Many unexpected findings have been made in recent years that challenge old concepts about these two human pathogens.

The intestinal epithelium stands as the first physical barrier that HAV and HEV must cross before either can enter the bloodstream and gain access to the liver (Peterson and Artis 2014). Despite epidemiologic evidence of efficient natural enteric transmission, the mechanisms by which these viruses penetrate the tight gut epithelial barrier are not known. There is no compelling evidence that HAV actually replicates in the gastrointestinal epithelium. HAV-related antigen was putatively detected by immunofluorescence microscopy in crypt cells of the small intestine shortly after per-oral challenge of New World owl monkeys (Aotus trivirgatus) (Asher et al. 1995), but a similar study of marmosets failed to show viral antigens in gut tissue (Mathiesen et al. 1980). Similar detailed studies have not been performed with HEV. Because there is a dearth of information on interactions of HAV and HEV with the gut, only events occurring in the liver, the main target for both viruses, will be considered here.

Editors: Stanley M. Lemon and Christopher Walker

Additional Perspectives on Enteric Hepatitis Viruses available at www.perspectivesinmedicine.org

Copyright (C) 2019 Cold Spring Harbor Laboratory Press; all rights reserved; doi: 10.1101/cshperspect.a033464

Cite this article as Cold Spring Harb Perspect Med 2019;9:a033464 


\section{INNATE IMMUNITY IN THE LIVER}

The liver is constantly exposed to food and microbial products coming from the intestine via the portal venous blood, and therefore hepatic immune responses are generally geared toward tolerance (Crispe 2009). However, the liver can mount robust immune responses on microbial infection. Liver resident cells, including hepatocytes, resident macrophages (Kupffer cells), sinusoidal endothelial cells, and stellate cells, express a variety of pattern recognition receptors (PRRs) that detect pathogen-associated molecular patterns (PAMPs). These include Toll-like receptors (TLRs) and retinoic acid activated gene I (RIG-I)-like RNA helicases (RLRs) (Pandey et al. 2014), as well as nucleotide-binding oligomerization domain (NOD)-like protein receptors (NLRs) that have both proinflammatory and regulatory activities (Guo et al. 2015; Coutermarsh-Ott et al. 2016). On ligand binding, PRRs assemble multiprotein complexes culminating in the production of antiviral cytokines and chemokines.

Hepatocytes, the primary cell type targeted by HAV and HEV for infection, express both RLRs and TLRs (Li et al. 2005). RIG-I and the melanoma differentiation-associated protein-5 (MDA5), two well -characterized RLRs, detect cytoplasmic single-stranded RNA (ssRNA) with a $5^{\prime} \mathrm{di}$ - or triphosphate moiety, and lengthy double-stranded RNA (dsRNA), respectively (Fig. 1) (Pandey et al. 2014). On RNA binding, both RIG-I and MDA5 recruit the mitochondriaassociated antiviral protein (MAVS) to assemble a "signalosome," which results in the activation of transcription factors (e.g., interferon [IFN] regulatory factor [IRF3], nuclear factor $\kappa B$ $[\mathrm{NF}-\mathrm{\kappa B}]$ ) leading to type I and type III IFN expression (Horner and Gale 2013). Hepatocytes also express TLR3, which senses dsRNA in an endosomal compartment and activates IRF3 and NF- $\kappa \mathrm{B}$ via the adaptor protein TIRdomain-containing adapter-inducing IFN- $\beta$ (TRIF) (Fig. 1) (Pandey et al. 2014). IFNs are secreted from the cell, subsequently binding to specific receptors on the cell surface and inducing hundreds of IFN-stimulated genes (ISGs). ISGs thus induced through both autocrine and paracrine signaling inhibit the replication and spread of viruses (Schoggins and Rice 2011). These cell-protective responses are augmented by the IFN-inducible protein kinase R (PKR), which is activated by viral dsRNA replication intermediates and which, by phosphorylating the translational initiation factor eIF $2 \alpha$, globally suppresses cellular protein synthesis (Garcia et al. 2006).

In additional to hepatocytes, other cell types that either reside in or are recruited to the liver during infection participate in the innate response to virus infection. For example, in addition to their role in antigen presentation, Kupffer cells and dendritic cells (DCs) express a variety of PRRs and produce antiviral cytokines and chemokines. Kupffer cells and monocytes express high levels of NLRs, which play important roles in mediating inflammatory responses and modulating liver injury (Dixon et al. 2013). Plasmacytoid DCs (pDCs), also known as professional IFN-producing cells, express high levels of TLR7 and TLR9 and rapidly produce high quantities of both type I and type III IFNs (within hours) on activation (Swiecki and Colonna 2015). The liver also contains highly abundant natural killer (NK) cells and NK T cells that produce IFN- $\gamma$ on activation and exhibit perforin-dependent cytotoxicity against virus-infected cells (Golden-Mason and Rosen 2013).

\section{INNATE IMMUNE RESPONSES TO HAV INFECTION}

\section{Innate Immune Responses in Hepatitis A}

With only very rare exceptions, HAV infection causes only short-term, acute liver injury. Fecal shedding of virus and viremia (both detected by reverse transcription polymerase chain reaction [RT-PCR]) may be prolonged for months in infected neonates and severely immunocompromised liver transplant recipients (Rosenblum et al. 1991; Foster et al. 2017), but such reports are very rare in the literature. The replication of wild-type HAV does not cause cytopathic effects in vitro or in vivo (Daemer et al. 1981; Binn et al. 1984; Hirai-Yuki et al. 2016a), and the disease is thought to be mediated by the 


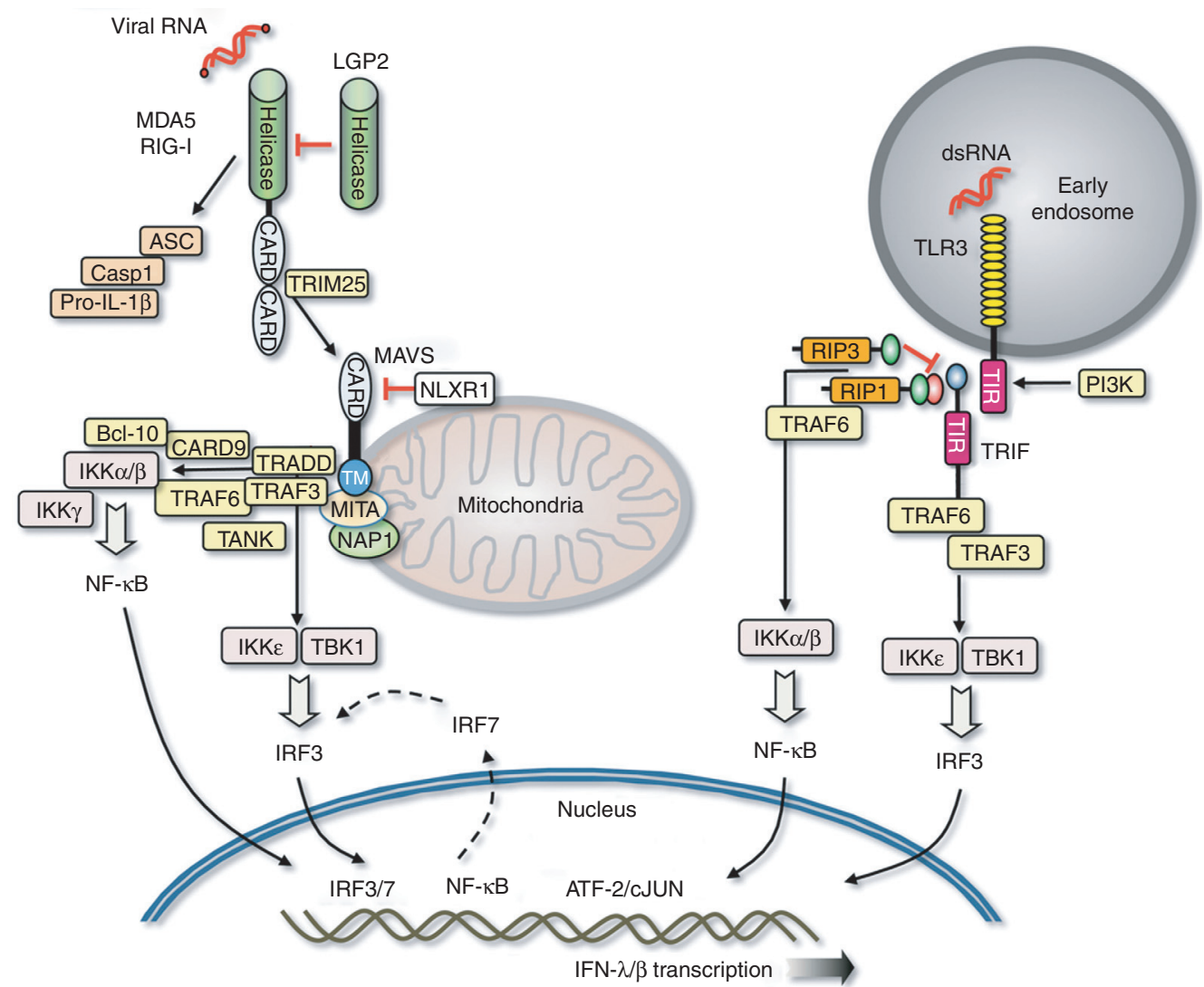

Figure 1. Innate immune signaling pathways leading to interferon (IFN) production in hepatocytes. The cytosolic retinoic acid activated gene I (RIG-I)-like helicases, melanoma differentiation-associated protein 5 (MDA5) and RIG-I, and endosomal Toll-like receptor (TLR) 3 are important pathogen recognition sensors within hepatocytes, signaling downstream through the adaptors mitochondria-associated antiviral protein (MAVS) and TIR-domaincontaining adapter-inducing IFN- $\beta$ (TRIF), respectively, inducing phosphorylation, dimerization, and, ultimately, nuclear translocation of the critical transcription factor IRF3 along with activation of nuclear factor (NF) $\kappa B$, resulting in transcription of type I (IFN- $\alpha / \beta$ ) and type III (IFN- $\lambda$ ) IFN genes. IL, Interleukin. (From Lemon 2010; adapted, with permission, from The American Society for Biochemistry and Molecular Biology @ 2010.)

host immune response to the virus (see Shin and Jeong 2018).

Although a number of nonhuman primate species are susceptible to HAV infection and have been used for many years to study pathogenesis (see Lanford et al. 2018), the innate immune response to acute HAV infection has not been carefully examined until recently. Lanford and colleagues reported the results of microarray assays documenting changes in the intrahepatic transcriptome during acute HAV infection in experimentally infected chimpanzees (Lanford et al. 2011). This study revealed
HAV to be remarkably stealthy. Only a very limited type I IFN response was detected in the liver of these animals, and only during the early stages of the infection, before peak replication of virus in the liver (Fig. 2A) (Lanford et al. 2011). These results are in sharp contrast to $\mathrm{HCV}$, which elicits robust innate responses within days after virus inoculation of chimpanzees (Fig. 3) (Bigger et al. 2001; Su et al. 2002), and confirm very early suggestions in the literature that hepatitis $\mathrm{A}$ is accompanied by a minimal IFN response (Taylor and Zuckerman 1968; Wheelock et al. 1968). 
Z. Feng and S.M. Lemon

A

$$
\begin{array}{ll}
\rightarrow \text { ISG15 } & \rightarrow \text { IFI35 } \\
\rightarrow \text { IFI6 } & \rightarrow \text { CXCL10 } \\
\leftarrow \text { IFI27 } & - \text { IFIT2 } \\
\rightarrow \text { IFIT1 } & - \text { OAS2 } \\
\rightarrow \text { IFIT3 } & \rightarrow \text { OAS3 } \\
\rightarrow \text { MX1 } & \rightarrow \text { ISG20 } \\
\rightarrow-\text { OAS1 } & \rightarrow \text { STAT1 } \\
\triangle \text { IFI44 } & \rightarrow \text { RSAD2 }
\end{array}
$$

B
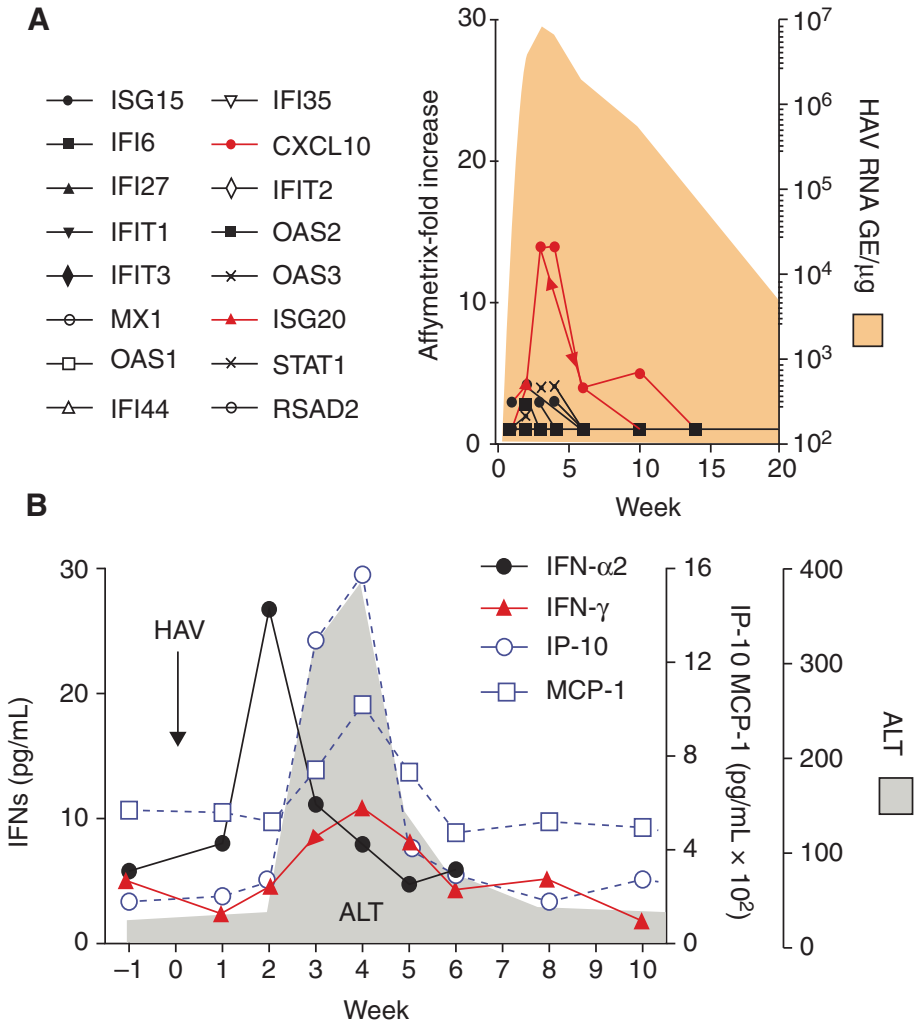

Figure 2. Intrahepatic interferon (IFN)-stimulated gene expression in a chimpanzee with experimental hepatitis A virus (HAV) infection. (A) Intrahepatic IFN-stimulated gene (ISG) messenger RNA (mRNA) expression, shown as fold change from baseline in Affymetrix GeneChip assays, in a chimpanzee (4x0395) infected experimentally with HAV. With the exception of CXCL10 (IP10) and ISG20, both of which are dually regulated by IFN$\alpha / \beta$ and IFN $-\gamma$, low-level ISG induction is restricted to the first weeks of infection, and subsides before peak HAV RNA abundance in the liver. (From Lanford et al. 2011; adapted, with permission, from the National Academy of Sciences (C) 2011.) (B) Early course of HAV infection in chimpanzee $4 x 0395$, showing alanine aminotransferase (ALT) elevation and IFN and cytokine detection in serum samples.

The early but limited expression of ISGs is associated with a brief period during which minimal amounts of IFN- $\alpha$ can be detected in serum from infected chimpanzees (Fig. 2B). This correlates temporally with the transient presence of pDCs in hepatic sinusoids (Feng et al. 2015). In vitro studies using human pDCs freshly isolated from buffy coats indicate that $\mathrm{pDCs}$ respond in a robust fashion, secreting type I IFN when exposed to quasi-enveloped virus (eHAV) (see McKnight and Lemon 2018), but not naked, nonenveloped HAV (Feng et al. 2015). eHAV is endocytosed rapidly and efficiently by pDCs. This is likely a result, at least in part, of recognition of phosphatidylserine
(PtdSer) residues on the surface of the quasienvelope by PtdSer receptors on the $\mathrm{pDC}$ membrane as it is partially blocked by annexin $\mathrm{V}$ (Feng et al. 2015). The early type I IFN response diminishes before peak replication of HAV within the liver and the onset of liver injury, when a type II IFN (IFN- $\gamma$ ) response becomes evident (Lanford et al. 2011; Zhou et al. 2012; Feng et al. 2015). Type III IFN (IFN- $\lambda$ ) responses induced by HAV infection have not been critically examined in the chimpanzee model.

Several attributes of HAV likely to contribute to its stealthy nature. The $5^{\prime}$ end of newly synthesized HAV RNAs are covalently linked to a small protein, VPg, which serves to prime 


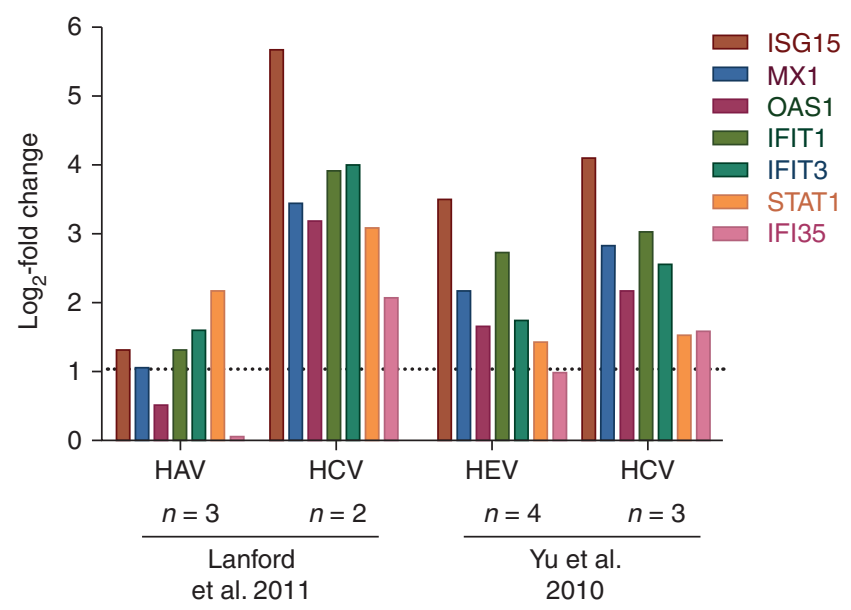

Figure 3. Comparative analysis of intrahepatic interferon (IFN)-stimulated genes (ISGs) expression resulting from infection with hepatitis $\mathrm{C}$ virus (HCV) versus hepatitis A virus (HAV) or hepatitis E virus (HEV) in chimpanzees. Columns reflect the average maximum-fold change for each of the indicated ISGs from baseline during the course of acute infection, as determined in two independent studies, one of HAV and the other of HEV. Data from HAV-infected animals are from Lanford et al. (2011), whereas HEV-infected animal data are from Yu et al. (2010). Contemporaneous data from chimpanzees with experimental HCV infection are shown for comparison from each of these two studies, both of which used Affymetrix GeneChips.

RNA synthesis (Weitz et al. 1986; McKnight and Lemon 2018). Although studies with other picornaviruses indicate that this is likely to be removed from incoming genomic RNA shortly after viral entry and uncoating, VPg may shield the $5^{\prime}$ end of newly synthesized RNAs from cytoplasmic RNA sensors such as RIG-I. In addition, the HAV genome terminates at its $3^{\prime}$ end in a poly(A) tract similar to cellular messenger RNAs (mRNAs). Thus, HAV RNA may be distinguished from host mRNAs only by the secondary structure within the $5^{\prime}$ untranslated (5'UTR) RNA (see McKnight and Lemon 2018), or by its duplex structure with minus-strand RNA (Myong et al. 2009; Schlee et al. 2009). The replication of HAV is very slow compared to other picornaviruses, possibly because of the low guanine-cytosine (GC) content of viral RNA and the fact that viral protein synthesis is dependent on codons that are relatively rarely used by host cells (see Pintó et al. 2018). Newly synthesized HAV genomes appear to be rapidly packaged into the viral capsid, leaving little free HAV RNA in the cytoplasm (Anderson et al. 1988). Both of these attributes could also limit the abundance of viral RNA available for detection by PAMP receptors.

HAV Actively Suppresses IFN Responses by Proteolytically Degrading MAVS and TRIF

In addition to these features that likely limit innate immune recognition, HAV actively disrupts signaling pathways leading to IFN production in infected cells (Fig. 4A) (Fensterl et al. 2005). Both cytoplasmic and endosomal RNAsensing pathways are checked by proteinases expressed by the virus. A virally encoded, catalytically active polyprotein processing intermediate, $3 \mathrm{ABC}$, degrades MAVS, a critical adaptor protein for signaling downstream of cytoplasmic RNA sensors, and thereby ablates RLRmediated induction of IFNs (Figs. 4B, top, and 5) (Yang et al. 2007). The mature, fully processed HAV $3 \mathrm{C}^{\text {pro }}$ protease (see McKnight and Lemon 2018) is normally distributed throughout the cytoplasm. However, when fused with $3 \mathrm{AB}$ in the processing intermediate, $3 \mathrm{ABC}$, it assumes a mitochondrial localization because of a mitochondrial membrane localization signal in the $3 \mathrm{~A}$ transmembrane domain (Yang 

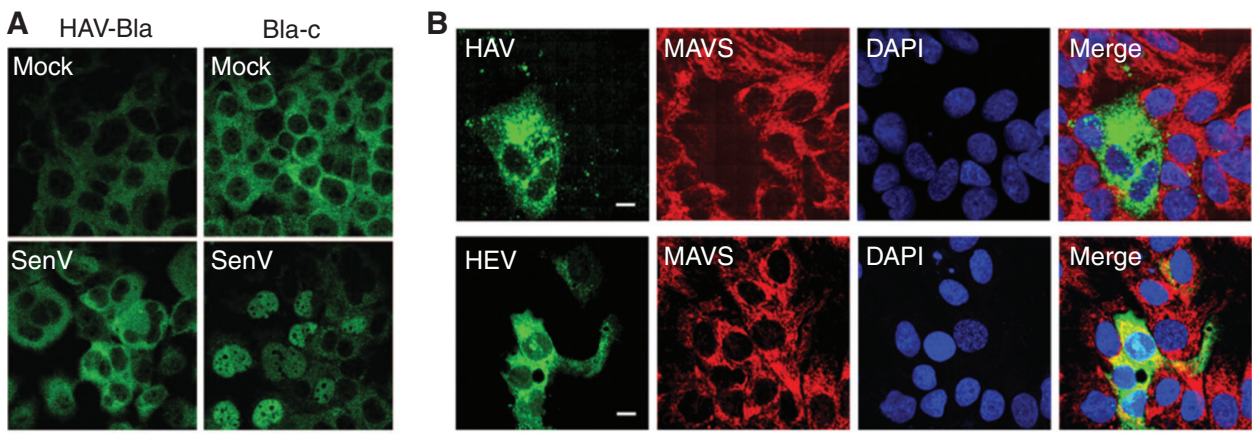

Figure 4. Hepatitis A virus (HAV) infection actively blocks virus-induced interferon (IFN) responses and degrades mitochondria-associated antiviral protein (MAVS). (A) Confocal fluorescence microscopic images of IFN-regulatory factor (IRF) 3 expression in a Huh7 cell line containing a replicating subgenomic HAV RNA (HAV-Bla cells) or its cured derivative lacking HAV RNA (Bla-C cells), following infection with Sendai virus (SenV), a potent retinoic acid activated gene I (RIG-I) agonist, or mock infection (Mock). IRF3 is predominantly nuclear in localization in Bla-C cells, indicating its activation, whereas it remains cytoplasmic in HAV-Bla cells because of disruption of RIG-I/MAVS signaling. (Panel $A$ from Yang et al. 2007; adapted, with permission, from the National Academy of Sciences (C) 2007.) (B) Confocal microscopic images showing MAVS and viral antigens in human liver-derived HepG2 cells infected with either HAV (top panels) or HEV (lower panels). MAVS expression is lost because of $3 \mathrm{C}^{\text {pro }}$ cleavage in HAV-infected cells, whereas MAVS abundance is not altered in HEV-infected cells. Nuclei are counterstained with 4', 6-diamidino-2-phenylindole (DAPI). (Panel B from Yin et al. 2017; adapted under the terms of the Creative Commons Attribution License, which permits unrestricted use.)

et al. 2007). In vitro, the cleavage of MAVS in $\mathrm{HAV}$-infected cells is complete, and cells no longer respond to exogenous RLR ligands.

A second catalytically active $3 C^{\text {pro }}$ processing intermediate, 3CD (see McKnight and Lemon 2018), cleaves the TLR3 adaptor protein TRIF (Fig. 5) (Qu et al. 2011). TRIF does not contain any canonical $3 C^{\text {pro }}$ dipeptide cleavage sites. However, when fused to the polymerase $3 \mathrm{D}^{\mathrm{pol}}$ in $3 \mathrm{CD}$, the $3 \mathrm{C}$ substrate specificity is altered such that it cleaves TRIF at two noncanonical sites ( $\mathrm{Qu}$ et al. 2011). It is interesting that the targeting of MAVS and TRIF for proteolytic degradation by HAV proteins mirrors the capacity of the phylogenetically unrelated $\mathrm{HCV}$ serine protease, NS3/4A, to degrade these same adaptor proteins (Lemon 2010). However, $3 C^{\text {pro }}$ also cleaves the regulatory subunit of the I $\kappa$ kinase complex, NF- $\kappa B$ essential modulator (NEMO) (Fig. 5) (Wang et al. 2014), disrupting NF- $\kappa$ B-mediated responses and further crippling the host's ability to produce IFN in HAV-infected cells.

Despite efficient cleavage of MAVS and TRIF, cultured cells infected with HAV may still develop at least a transient IFN response initi- ated by RIG-I or TLR3 (Yang et al. 2007; Qu et al. 2011; Sung et al. 2017). This may occur before a significant fraction of MAVS or TRIF are degraded by the viral proteases. ISG responses could also result from TLR3 sensing of dsRNA in uninfected hepatocytes following endocytosis of replication intermediates released by neighboring infected cells (Dansako et al. 2013). Class A scavenger receptor proteins such as MSR1 play key roles in this process, facilitating the endocytosis of viral RNA that is then detected by endosomal TLR3 (DeWitte-Orr et al. 2010; Dansako et al. 2013). Macrophages could similarly contribute to the IFN response via TLR3 within the liver, as there is little evidence that they are actively infected and express HAV proteases. Plasmacytoid dendritic cells also sense eHAV via TLR7, as mentioned above, and respond with production of type I IFN in a MAVS- and TRIF-independent fashion (Feng et al. 2015).

Early studies showed that HAV can be eradicated from infected fibroblasts by treatment with either IFN- $\alpha$ or IFN- $\beta$ (1000 IU/ $\mathrm{mL}$ ) (Vallbracht et al. 1984), whereas more recent data indicate that HAV RNA replication is inhibited by recombinant IFN- $\alpha 2 \mathrm{~B}$ at an $\mathrm{EC}_{50}$ of 


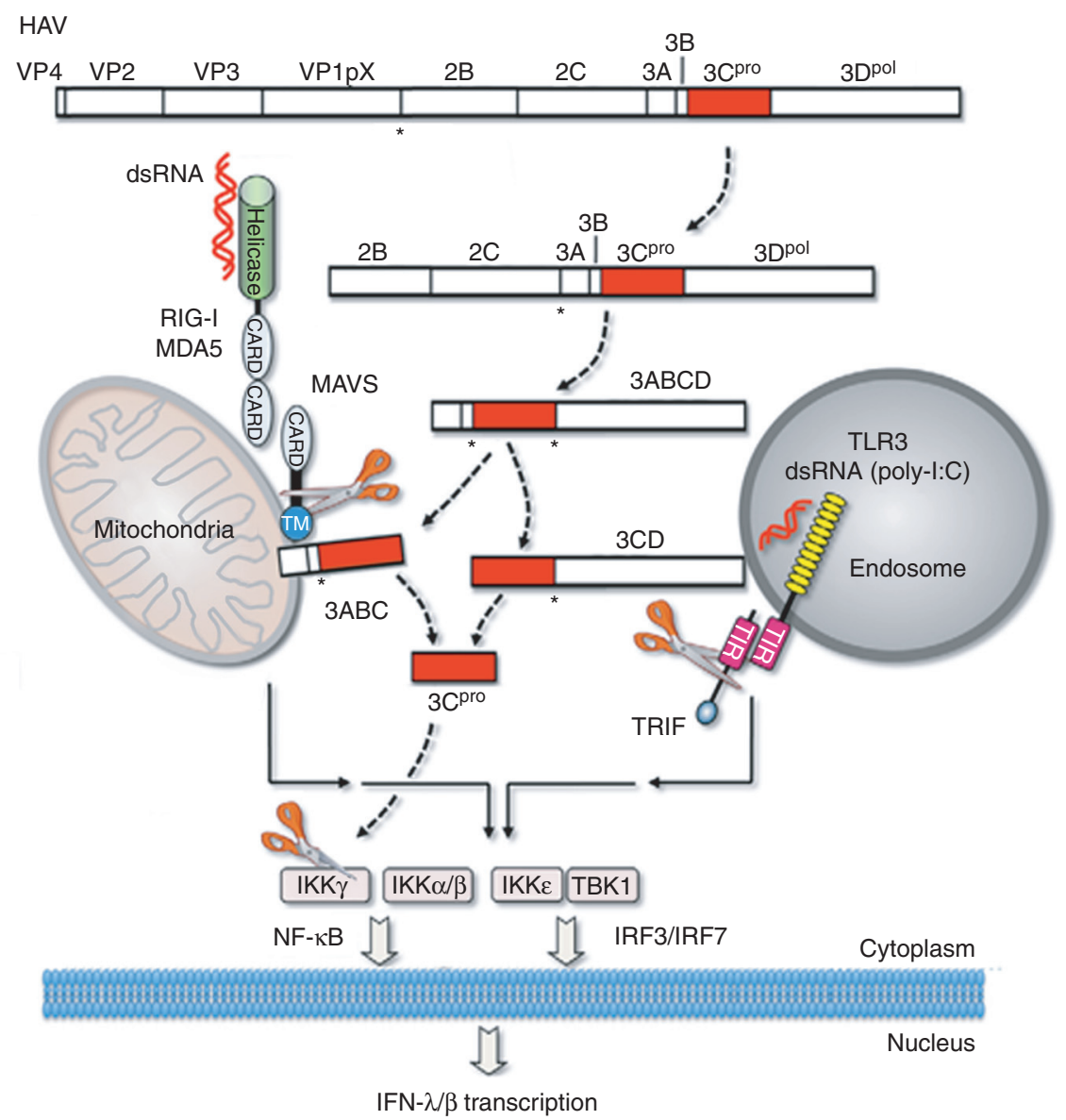

Figure 5. Hepatitis A virus (HAV) proteases degrade key innate immune signaling proteins: mitochondria-associated antiviral protein (MAVS), TIR-domain-containing adapter-inducing interferon (IFN) (TRIF), and nuclear factor (NF)- $\mathrm{BB}$ essential modulator (NEMO) (IKK $\gamma)$. Schematic showing how HAV polyprotein processing intermediates with $3 \mathrm{C}^{\text {pro }}$ catalytic activity cleave MAVS (3ABC), TRIF (3CD), and NEMO also known as IKK $\gamma$ (mature $3 \mathrm{C}^{\mathrm{pro}}$ ), thereby disrupting signaling leading from pathogen-associated molecular pattern (PAMP) sensors to the critical transcription factors IFN-regulatory factor (IRF) 3 and NF- $\kappa B$ that drive type I and III IFN expression.

$\sim 100 \mathrm{U} / \mathrm{mL}$ (Yang et al. 2007). Thus, the capacity of HAV to infect cells is likely to be very dependent on its ability to block IFN responses.

\section{Inflammasome Activation and NLR Proteins in Hepatitis A}

In addition to RLRs and TLRs, NLRs can play an important role in the host response to infections by RNA viruses, both promoting and suppressing innate immunity and inflammation (Wen et al. 2013; Jha and Ting 2015). The NLRs are a large protein family containing evolutionarily conserved domains involved in sensing and responding to cellular stress and pathogen invasion. NLRP3 (also known as cryopyrin, NALP3, or CIAS1) is the best-studied NLR protein, and it is pivotal for elaboration of interleukin (IL)-1 $\beta$ and IL-18 by macrophages in response to a broad spectrum of RNA viruses, including picornaviruses (Rajan et al. 2011). NLRP3 acts as a component of a multimolecular "inflammasome" complex that mediates cleavage of procaspase-1 to caspase-1 (Dowling and O’Neill 2012). Inflammasome assembly leads to maturation of caspase-1, which processes 
pro-IL-1 $\beta$ and pro-IL-18 to their mature, biologically active forms.

Relatively little is known about the role of NLR proteins in viral hepatitis, including hepatitis A and E. However, HCV has been reported to induce inflammasome assembly and IL-1 $\beta$ secretion mediated by NLRP3 in a differentiated human macrophage (THP-1) cell line (Negash et al. 2013). Such a response, mediated by Kupffer cells, could contribute to the inflammatory response in hepatitis C. In contrast, unpublished data from our laboratory indicate that exposure to either eHAV or HAV neither initiates nor blocks NLRP3 inflammasome assembly or IL- $1 \beta$ secretion by THP- 1 cells ( $Z$ Feng and $\mathrm{SM}$ Lemon, unpubl.). Despite an IFN- $\gamma$ response and (likely) activation of NF- $\mathrm{BB}$ during the inflammatory phase of the infection (which can drive pro-IL- $1 \beta$ transcription), serum IL- $1 \beta$ levels are not prominently elevated either in experimentally infected chimpanzees or in infected Ifnar $1^{-/-}$mice (Lanford et al. 2011; Hirai-Yuki et al. 2016a). In contrast, other cytokines, such as IP10 (CXCL10) and MCP-1, are prominently elevated in these animal models of hepatitis A, as well as in infected humans (Lanford et al. 2011; Hirai-Yuki et al. 2016a; Sung et al. 2017; Shin and Jeong 2018).

Nonetheless, other NLR proteins contribute to cytokine responses evoked by HAV infection. Recent data from our laboratory indicate that NLRX1 positively regulates very early $(3 \mathrm{~h})$, RLR-induced cytokine responses to HAV in $\mathrm{T}$ antigen-transformed adult human hepatocytes (Feng et al. 2017). NLRX1 is usually considered a negative regulator of innate immunity (Allen et al. 2011), but we found it to promote IL-6 and other early cytokine responses by inhibiting activation of the dsRNA-induced PKR. Suppression of PKR activation allows for early, virusinduced increases in synthesis of IRF1 protein, which plays a key role in regulating these cytokine responses in hepatocytes (Feng et al. 2017). In the absence of NLRX1, translation of IRF1 mRNAs is blocked by PKR-mediated global shutdown of cellular protein synthesis. NLRX1 appears to compete with $\mathrm{PKR}$ for binding to dsRNA, thereby reducing PKR activation. NLRX1 is likely to similarly regulate the synthe- sis of ISG proteins in hepatocytes infected with $\mathrm{HAV}$, as well as HCV (Garaigorta and Chisari 2009; Feng et al. 2017). These recent findings point to the extreme complexity with which virus-activated intrahepatic innate immune pathways activated are regulated.

\section{The Role of Innate Immunity in Host Range Restriction and HAV Pathogenesis}

The importance of type I IFNs in host defenses against HAV infection was recently confirmed in a novel murine model of human hepatitis $A$ (Hirai-Yuki et al. 2016a). Normal C57Bl6 mice are not susceptible to intravenous challenge with wild-type HAV, but Ifnar $1^{-1-}$ mice that lack expression of the receptor for type I IFNs are susceptible to infection and develop acute hepatitis with histopathologic features typical of the disease in humans, including numerous apoptotic hepatocytes (see Hirai-Yuki et al. 2018). HAV failed to infect Ifngr $1^{-/-}$mice lacking the type II IFN receptor, indicating that type I IFNs, but not type II IFNs, are a major barrier for cross-species infection by HAV. Mice lacking MAVS, but not TRIF, were also susceptible to HAV (Hirai-Yuki et al. 2016a). This suggests that MAVS-dependent, RLR-induced IFN responses play a much more important role in restricting HAV replication than TLR3 in vivo, at least in mice, despite the fact that HAV targets adaptors in both signaling pathways for degradation (Fig. 5). Mice lacking expression of both IRF3 and the redundant transcription factor, IRF7, were also susceptible to HAV infection (Hirai-Yuki et al. 2016a).

Interestingly, unlike Ifnar $1^{-/-}$mice that developed histologic evidence of hepatitis with high serum ALT elevations, HAV-infected Mavs $^{-1-}$ and $\operatorname{Irf} 3^{-1-} \operatorname{Irf7}^{-/-}$mice showed little or no evidence of disease despite replicating virus to higher titers in the liver than infected Ifnar $1^{-/-}$mice (Hirai-Yuki et al. 2016a). These results show that liver injury in HAV-infected mice is not dependent on IFN-mediated responses, but rather results from the activation of MAVS and IRF3/7 leading to hepatocellular apoptosis. This could result from expression of proapoptotic ISGs in the infected liver, some of which can be directly transcriptionally activated 
by IRF3 without the need for IFNs or Janus tyrosine kinase/signal transducers and activators of transcription (JAK/STAT) signaling (Grandvaux et al. 2002). One such ISG is IFNinduced protein with tetratricopeptide repeats 2 (IFIT2), which was highly induced in HAV-infected Ifnarl ${ }^{-1-}$ mice (Hirai-Yuki et al. 2016a). Human IFIT2 has been shown to promote mitochondrial apoptosis when expressed in murine cells (Stawowczyk et al. 2011; Reich 2013).

Alternatively, HAV-induced hepatocellular apoptosis could result from a transcriptionindependent function of IRF3 in infected Ifnar $1^{-/-}$mice. When activated by RLRMAVS signaling, IRF3 is ubiquitylated by the linear polyubiquitylating enzyme complex, LUBAC, resulting in a direct interaction between the BH3 domain of IRF3 and the mitochondrial protein, Bax, thereby inducing apoptosis (Chattopadhyay et al. 2013, 2016). This proapoptotic activity of IRF3 is termed RLR-induced IRF3mediated pathway of apoptosis (RIPA). Additional studies are needed to determine the exact mechanism of IRF3-induced liver injury in this murine model, but it is interesting that acute ethanol-induced liver injury has also been linked to IRF3 activation (Petrasek et al. 2013).

\section{INNATE IMMUNE RESPONSES TO HEV INFECTION}

Like HAV, HEV causes acute, self-limited infection in humans. However, HEV can persist in persons with a weakened T-cell immunity, particularly those who have received solid organ transplantation or those infected with human immunodeficiency virus (HIV) (see Kamar and Pischke 2018). This is indicative of a key difference in host control of HEV and HAV infections. Innate immune responses during acute and chronic HEV infections are particularly poorly understood and have not been studied intensively.

\section{Innate Immunity in Animal Models of HEV} Infection

There are multiple HEV genotypes, at least four of which cause disease in humans. These differ
Innate Immunity to Enteric Hepatitis Viruses

in their geographic distribution, epidemiology, and pathogenesis (Emerson and Purcell 2003; Dalton and Izopet 2018; Nelson et al. 2018). Genotype 1 (gt1) and gt2 HEV cause endemic and epidemic waterborne infections in developing countries, whereas gt 3 and gt 4 HEV are zoonotic and mostly found in developed countries. HEV gt3 is responsible for the majority of chronic HEV cases. Studies in nonhuman primates have shown that gt1 HEV and gt2 have greater infectivity and virulence than gt 3 and gt 4 (Purcell et al. 2013). In mice with chimeric human livers, gt1 HEV also replicates much more efficiently than gt3 HEV (Allweiss et al. 2016; van de Garde et al. 2017). Currently, it is not clear whether the lower replication efficiency of gt 3 is because of a restriction mediated by a stronger host innate response, or simply an intrinsic property of the virus.

Using Affymetrix microarrays, $\mathrm{Yu}$ et al. (2010) examined the intrahepatic transcriptional response to gt $1 \mathrm{HEV}$ in experimentally infected chimpanzees. A rough comparison of the results of this study with the similar study of HAV-infected chimpanzees conducted by Lanford et al. (2011) described above suggests that the IFN response to HEV may be somewhat stronger than in HAV infection and closer to that induced by acute HCV infection (Fig. 3). Elevated ISG expression is detected in the sera of patients with chronic HEV infection (Moal et al. 2013), as well as in the liver of HEV-infected chimeric mice engrafted with human hepatocytes, where adaptive immunity is absent (Sayed et al. 2016). Whereas a very recent study reported no induction of intrahepatic ISGs in humanized uPA/NOG mice infected with either gt1 or gt3 HEV (van de Garde et al. 2017), it is important to note that the earliest time point examined was 2 weeks after HEV inoculation. An early, transient IFN response could have been missed.

\section{Innate Immune Responses to HEV in Cultured Cells}

During its replication, HEV generates a subgenomic RNA for translation of the structural proteins (see Kenney and Meng 2018). Both the 
HEV RNA genome and the subgenome are capped at their $5^{\prime}$ end with a 7-methylguanosine cap (similar to cellular mRNAs), and the 5'UTR RNA segment is much shorter and less structured than in the HAV genome. The $3^{\prime}$ UTR of both HEV RNAs terminates in a lengthy poly (A) tract. In essence, the HEV genome and subgenomic RNA are very similar to host mRNAs in their structure, more so than in HAV, which would be expected to help the virus evade detection by cytoplasmic RNA sensors.

Nonetheless, HEV infection induces ISGs in a number of different types of cultured cells, including human lung epithelial cells (A549) (Devhare et al. 2013), human hepatotoma cells (PLC/PRF/5 and HepG2) (Zhang et al. 2014; Yin et al. 2017), primary human hepatocytes (Yin et al. 2017), and human embryonic stem cells/induced pluopotent stem cell-derived hepatocyte-like cells (Helsen et al. 2016). HEV has not been shown to have the capacity to proteolytically degrade host proteins engaged in signaling downstream of PAMP receptors, as HAV and HCV do. Consistent with this, MAVS abundance is not altered in cells transfected with replication-competent HEV RNAs (Fig. 4B, bottom), although the response to RIG$\mathrm{I}$ and MDA5 agonists is reduced in such cells (Nan et al. 2014b; Yin et al. 2016). The underlying mechanism is uncertain, but overexpression of the papain-like cysteine protease (PCP) domain of the HEV open reading frame (ORF)1 protein has been shown to result in deubiquitination of RIG-I and TBK1, thereby blocking RIG-I signaling (Nan et al. 2014b). The X domain of the ORF1 polyprotein also appears to act on an independent step in the induction of IFN, inhibiting RIG-I-induced phosphorylation of IRF3 (Nan et al. 2014b). These findings suggest that HEV replication impedes IFN induced via activation of RIG-I-like helicases. The deubiquitinase activity of the PCP domain may extend also to host proteins conjugated to the ubiquitin-like ISG15 (Karpe and Lole 2011).

Proteins expressed from the other two HEV ORFs have also been suggested to modulate IFN responses. Overexpression of the ORF2 protein in hepatoma cells stabilized $\mathrm{I} \kappa \mathrm{B} \alpha$, thereby reducing NF- $\kappa \mathrm{B}$ activity (Surjit et al. 2012).
ORF3 has similarly been reported to reduce TLR3-induced NF- $\kappa \mathrm{B}$ activity (He et al. 2016). On the other hand, ORF3 was reported to interact with RIG-I and enhance its ubiquitination, and also boost poly-(I:C)-induced IFN- $\beta$ expression (Nan et al. 2014a). The contradictory findings reported in these studies likely reflect the hazards of relying on protein overexpression and highlight the need for a robust cell culture system for HEV that accurately recapitulates events in the liver.

\section{Interferon Resistance of HEV in Persistently Infected Cells}

Importantly, HepG2 cells that were persistently infected with gt $3 \mathrm{HEV}$ or that harbored an HEV replicon RNA, were found to continuously produce type III IFNs (Yin et al. 2016). The cellular response to this IFN and resulting ISG expression was insufficient to eliminate the HEV RNA, despite continuous stimulation of the JAK/STAT pathway. Under these conditions, $\mathrm{HEV}$ infection was refractory to even high concentrations of IFNs, persisting despite treatment with $100 \mathrm{ng} / \mathrm{mL}\left(2 \times 10^{5} \mathrm{U} / \mathrm{mL}\right)$ of recombinant IFN- $\alpha 2 \mathrm{a}$ (Yin et al. 2016). HEV itself does not appear to interfere with JAK/STAT signaling, as blocking IFN production by RNAi-mediated depletion of MAVS largely restored the responsiveness of HEV-infected cells to both type I and type III IFNs. Nor does HEV block ISG protein synthesis, as the abundance of several ISGs (e.g., RIG-I, ISG56) was substantially increased in cells supporting HEV replication. How HEV maintains its replication capacity in the presence of ongoing IFN responses is unclear, but it is possible that the resistance to exogenous IFN stems at least in part from continuous stimulation of the IFN receptor (Sarasin-Filipowicz et al. 2009).

The ability of gt $3 \mathrm{HEV}$ to persist in cell culture in the presence of an IFN response and to resist treatment with exogenous IFNs may be important to the pathogenesis of HEV infection and virus persistence in patients with a weakened immune system. Commonly used immunosuppressive drugs suppress adaptive T-cell immunity but not innate IFN responses. Thus the hepatocytes infected with HEV in such pa- 
tients are likely to produce IFNs, as are different types of immune cells (e.g., pDCs, NK cells) in the chronically HEV-infected liver (Yu et al. 2010). The ability of HEV to continue to replicate in the presence of IFNs may facilitate its persistence as long as T-cell function is impaired.

\section{CONCLUDING REMARKS}

Although both HAV and HEV are transmitted enterically and cause similar clinical presentations, they use different strategies to counteract host IFN responses. HAV actively blocks IFN production in infected cells, whereas HEV appears capable of persisting despite the expression of multiple antiviral ISGs (Fig. 6). This unique ability of $\mathrm{HEV}$ may facilitate its persis- tence in vivo. Recent success in developing a mouse model for HAV offers new opportunities to investigate the pathogenesis of hepatitis $A$, and may conceptually aid our understanding of $\mathrm{HEV}$ pathogenesis. Numerous questions await future investigation.

\section{How Important Is It for Hepatitis Viruses to Block IFN Production in Hepatocytes?}

Efficient cleavage of MAVS and TRIF is not unique to HAV, because MAVS and TRIF are also degraded in $\mathrm{HCV}$-infected cells by the viral NS3/4B protease (Lemon 2010). The fact that both viruses target both adaptors suggests that the disruption of IFN production via these pathways may be critical to enable hepatotropic
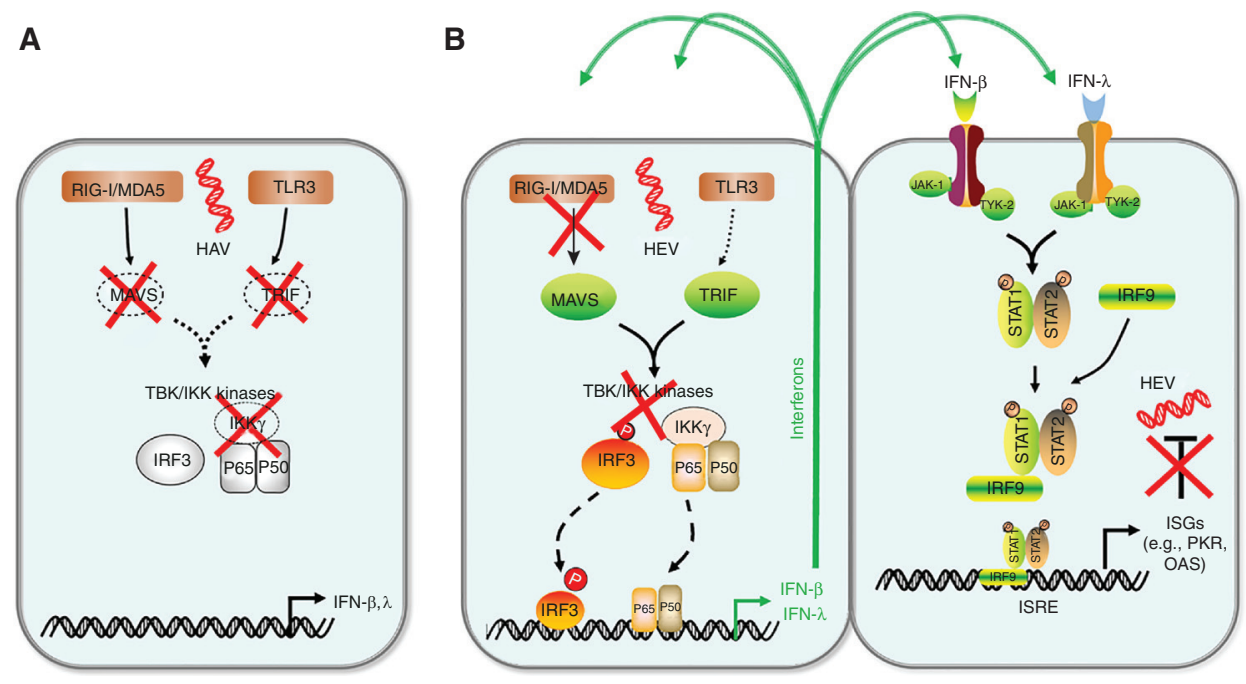

Figure 6. Contrasting strategies for disrupting interferon (IFN)-mediated responses in hepatitis A virus (HAV) versus hepatitis E virus (HEV) infections. (A) In HAV-infected cells, viral double-stranded RNA (dsRNA) replication intermediates are sensed by cytosolic retinoic acid activated gene I (RIG-I)-like RNA (RLRs) (RIG-I and melanoma differentiation-associated protein 5 [MDA5]) as well as endosomal Toll-like receptor (TLR)3. However, the adaptor proteins mitochondria-associated antiviral protein (MAVS) and TIR-domaincontaining adapter-inducing IFN- $\beta$ (TRIF), and the regulatory subunit of the I $\mathrm{B}$ kinase complex, NF- $\kappa \mathrm{B}$ essential modulator (NEMO), are degraded by viral proteinases (Fig. 5), disrupting signals extending from RLRs and TLR3 such that little or no activated IFN-regulatory factor (IRF) 3 and nuclear factor (NF)- $\kappa \mathrm{B}$ cells reach responsive promoters in the nucleus, and very little or no IFNs are produced. $(B)$ In contrast, in HEVinfected cells, HEV RNA is recognized by RIG-I and MDA5, and possibly by TLR3 as well. Signaling pathways may be impeded by open reading frame (ORF) 1 papain-like cysteine protease (PCP) domain antagonism of RIGI activation and X domain inhibition of IRF3 phosphorylation, but they are not disrupted and substantial amounts of IFNs (predominantly IFN- $\lambda$ ) are produced. Secreted IFNs bind to their receptors on the surface of infected cells and induce IFN-stimulated gene (ISG) expression via the Janus tyrosine kinase/signal transducers and activators of transcription (JAK/STAT) pathway in both an autocrine and paracrine fashion. Despite this activation of JAK/STAT signaling, HEV replication persists. 
viruses to establish infection $(\mathrm{Qu}$ and Lemon 2010). HEV also, as described above, may impede RLR-induced MAVS signaling via the PCP and $\mathrm{X}$ domains of ORF1 (Nan et al. 2014b). In addition, although it is a DNA virus, HBV replicates its genome via an RNA intermediate and has been reported recently to block MAVS function to suppress IFN production (Khan et al. 2016). Whereas the latter finding remains to be confirmed, these observations suggest that disruption of RIG-I/MAVS signaling may be especially important for RNA viruses infecting hepatocytes. Is this to reduce pathogenicity, given the role of MAVS in liver inflammation in the murine model of hepatitis A (Hirai-Yuki et al. 2016a), or to enhance viral replication, or both? A particularly interesting question is whether distantly related hepatoviruses identified recently in bats, which are separated from humans by over 80 million years of evolution (Drexler et al. 2015; Sander et al. 2018), similarly target the orthologs of these innate immune adaptor proteins for degradation in their host species.

\section{How Does HEV Persist in the Face of Active IFN Responses?}

While HEV may be less capable of blocking MAVS signaling than HAV, the virus persists in HEV-infected cell cultures despite the continuous production of type III IFN (Fig. 6) (Yin et al. 2016). How does the virus do this? HEV RNA replication is relatively resistant to both IFN- $\alpha$ and IFN- $\lambda$ compared to HCV, with an IFN- $\alpha 2 \mathrm{a} \mathrm{EC}_{50}$ more than 100-fold higher in comparative studies of subgenomic replicon RNAs (Todt et al. 2016; Wang et al. 2016). Good comparative studies of HAV and HEV would be of interest, especially studies looking at the complete viral life cycle. The mechanisms by which HEV resists IFN-mediated antiviral responses are unknown, and need to be explored.

What Are the Roles of Type I IFNs versus Type III IFNs in Innate Immune Responses to HAV and HEV?

Although type I IFNs clearly play a pivotal role in restricting HAV infection in mice (Hirai-Yuki et al. 2016a), type III IFNs are predominantly detected in cultured human hepatocytes infected with HAV, HBV, HCV, or HEV (Sheahan et al. 2014; Sato et al. 2015; Sung et al. 2017; Yin et al. 2017). This apparent discrepancy is likely because of a species difference. Human hepatocytes produce and respond robustly to IFN- $\lambda$ as noted above, but mouse hepatocytes express negligible amounts of the receptor for type III IFN and respond poorly to IFN- $\lambda$ (Pott et al. 2011; Hermant et al. 2014). Thus, while Ifnar $1^{-1-}$ mice provide a useful model for studying the pathogenesis of hepatitis A, this speciesspecific difference indicates a need for caution when considering the roles of the various types of IFNs. Studies are needed in Ifnlr $1^{-/-}$mice lacking functional expression of the type III IFN receptor, and in mice with dual knockouts of both the type I and type III receptors.

\section{Do Polymorphisms in Type III IFNs Influence HAV or HEV Infection Outcome?}

Polymorphisms in type III IFN genes have been associated with spontaneous and treatment-induced HCV clearance in humans (Ge et al. 2009; Thomas et al. 2009; Prokunina-Olsson et al. 2013). Whether such type III IFN polymorphisms also play a role in modulating HAV and HEV infection is not known. Some patients with chronic HEV infection clear the virus after withdrawal of immunosuppressive therapy, whereas others do not. It would be of interest to determine whether type III IFN polymorphisms are associated with clearance versus persistence of HEV, or fulminant disease in patients with either HAV or HEV infection.

\section{Does Gut Innate Immunity Play a Role in HAV or HEV Pathogenesis?}

We were unable to infect Ifnar ${ }^{-/-}$mice with HAV administered by gavage, even using $1000 \times$ the minimal intravenous (i.v.) infectious dose (Hirai-Yuki et al. 2016a). This seems surprising, because HAV is typically transmitted fecalorally, yet other studies have shown that the oral infectious dose of virus in chimpanzees is $10^{4.5}$-fold higher than the i.v. infectious dose 
Innate Immunity to Enteric Hepatitis Viruses

(Purcell et al. 2002). We also found no evidence of replication in the ileum or colon of productively infected Ifnarl $^{-1-}$ or $\mathrm{Mavs}^{-1-}$ mice (Hirai-Yuki et al. 2016a). Bile from infected mice contains abundant virus, indicating that fecally shed virus is produced in the liver, as in primates (Schulman et al. 1976; Hirai-Yuki et al. 2016b). Whereas the apparent lack of permissiveness of the gastrointestinal epithelium for HAV infection could reflect the absence of a key virus receptor, a plausible alternative hypothesis is that type III IFN responses might restrict $\mathrm{HAV}$ replication in the gut, as is the case for murine rotavirus and norovirus (Pott et al. 2011; Nice et al. 2015). It would not be surprising to find that type III IFNs restrict HAV replication in the murine gut, whereas type I IFN does so in the liver. Ifnar $1^{-1-}$ and Ifnlr $1^{-/-}$mice should prove useful in investigating these possibilities.

\section{Do Either HAV or HEV Replicate in the Gut?}

Determining whether either HAV or HEV replicates in the gut will be central to understanding the pathogenesis of these enteric hepatitis viruses. As described above, data addressing this question are sparse. It is possible that these viruses traverse the gut epithelium by transcytosis across microfold cells ( $\mathrm{M}$ cells) associated with Peyer's patches in the distal small intestine, a mechanism suggested previously for both poliovirus and HIV (Hocini and Bomsel 1999; Ouzilou et al. 2002). There is some evidence that HAV can undergo transcytosis, particularly if facilitated by immunoglobulin A (IgA) antibody to the virus (Counihan and Anderson 2016). The recent development of stem-cellderived human enteroids should provide an excellent tool to study the interactions between enteric hepatitis viruses and gastrointestinal tissues. Human enteroids phenotypically and functionally recapitulate the human intestinal epithelium in vivo, and support infection by a number of enteric viruses, including human norovirus, a virus known to be notoriously difficult to propagate in cell culture (Ettayebi et al. 2016).

\section{REFERENCES}

* Reference is also in this collection.

Allen IC, Moore CB, Schneider M, Lei Y, Davis BK, Scull MA, Gris D, Roney KE, Zimmermann AG, Bowzard JB, et al. 2011. NLRX1 protein attenuates inflammatory responses to infection by interfering with the RIG-IMAVS and TRAF6-NF- $\kappa$ B signaling pathways. Immunity 34: 854-865.

Allweiss L, Gass S, Giersch K, Groth A, Kah J, Volz T, Rapp G, Schobel A, Lohse AW, Polywka S, et al. 2016. Human liver chimeric mice as a new model of chronic hepatitis $\mathrm{E}$ virus infection and preclinical drug evaluation. J Hepatol 64: 1033-1040.

Anderson DA, Ross BC, Locarnini SA. 1988. Restricted replication of hepatitis A virus in cell culture: Encapsidation of viral RNA depletes the pool of RNA available for replication. J Virol 62: 4201-4206.

Asher LVS, Binn LN, Mensing TL, Marchwicki RH, Vassell RA, Young GD. 1995. Pathogenesis of hepatitis A in orally inoculated owl monkeys (Aotus trivergatus). J Med Virol 47: 260-268.

Bigger CB, Brasky KM, Lanford RE. 2001. DNA microarray analysis of chimpanzee liver during acute resolving hepatitis C virus infection. J Virol 75: 7059-7066.

Binn LN, Lemon SM, Marchwicki RH, Redfield RR, Gates NL, Bancroft WH. 1984. Primary isolation and serial passage of hepatitis A virus strains in primate cell cultures. J Clin Microbiol 20: 28-33.

Chattopadhyay S, Fensterl V, Zhang Y, Veleeparambil M, Yamashita M, Sen GC. 2013. Role of interferon regulatory factor 3-mediated apoptosis in the establishment and maintenance of persistent infection by Sendai virus. J Virol 87: 16-24.

Chattopadhyay S, Kuzmanovic T, Zhang Y, Wetzel JL, Sen GC. 2016. Ubiquitination of the transcription factor IRF3 activates RIPA, the apoptotic pathway that protects mice from viral pathogenesis. Immunity 44: 1151-1161.

Counihan NA, Anderson DA. 2016. Specific IgA enhances the transcytosis and excretion of hepatitis A virus. Sci Rep 6: 21855 .

Coutermarsh-Ott S, Eden K, Allen IC. 2016. Beyond the inflammasome: Regulatory NOD-like receptor modulation of the host immune response following virus exposure. J Gen Virol 97: 825-838.

Crispe IN. 2009. The liver as a lymphoid organ. Annu Rev Immunol 27: 147-163.

Daemer RJ, Feinstone SM, Gust ID, Purcell RH. 1981. Propagation of human hepatitis A virus in African Green Monkey kidney cell culture: Primary isolation and serial passage. Infect Immun 32: 388-393.

* Dalton HR, Izopet J. 2018. The transmission of epidemiology of hepatitis E virus genotype 3 and 4 infections. Cold Spring Harb Perspect Med doi: 10.1101/cshperspect. a032144.

Dansako H, Yamane D, Welsch C, McGivern DR, Hu F, Kato N, Lemon SM. 2013. Class A scavenger receptor 1 (MSR1) restricts hepatitis $\mathrm{C}$ virus replication by mediating tolllike receptor 3 recognition of viral RNAs produced in neighboring cells. PLoS Pathog 9: e1003345. 
Devhare PB, Chatterjee SN, Arankalle VA, Lole KS. 2013. Analysis of antiviral response in human epithelial cells infected with hepatitis E virus. PLoS ONE 8: e63793.

DeWitte-Orr SJ, Collins SE, Bauer CM, Bowdish DM, Mossman KL. 2010. An accessory to the "Trinity": SR-As are essential pathogen sensors of extracellular dsRNA, mediating entry and leading to subsequent type I IFN responses. PLoS Pathog 6: e1000829.

Dixon LJ, Barnes M, Tang H, Pritchard MT, Nagy LE. 2013. Kupffer cells in the liver. Compr Physiol 3: 785-797.

Dowling JK, O’Neill LA. 2012. Biochemical regulation of the inflammasome. Crit Rev Biochem Mol Biol 47: 424-443.

Drexler JF, Corman VM, Lukashev AN, van den Brand JMA, Gmyl A, Brunink S, Rasche A, Seggewiss N, Feng H, Leijten LM, et al. 2015. Evolutionary origins of hepatitis A virus in small mammals. Proc Natl Acad Sci 112: 15190-15195.

Emerson SU, Purcell RH. 2003. Hepatitis E virus. Rev Med Virol 13: 145-154.

Ettayebi K, Crawford SE, Murakami K, Broughman JR, Karandikar U, Tenge VR, Neill FH, Blutt SE, Zeng XL, Qu L, et al. 2016. Replication of human noroviruses in stem cellderived human enteroids. Science 353: 1387-1393.

Feng Z, Li Y, McKnight KL, Hensley L, Lanford RE, Walker CM, Lemon SM. 2015. Human pDCs preferentially sense enveloped hepatitis A virions. J Clin Invest 125: 169-176.

Feng H, Lenarcic EM, Yamane D, Wauthier E, Mo J, Guo H, McGivern DR, Gonzalez-Lopez O, Misumi I, Reid LM, et al. 2017. NLRX1 promotes immediate IRF1-directed antiviral responses by limiting dsRNA-activated translational inhibition mediated by PKR. Nat Immunol 18: 1299-1309.

Fensterl V, Grotheer D, Berk I, Schlemminger S, Vallbracht A, Dotzauer A. 2005. Hepatitis A virus suppresses RIG-Imediated IRF-3 activation to block induction of $\beta$ interferon. J Virol 79: 10968-10977.

Foster MA, Weil LM, Jin S, Johnson T, Hayden-Mixson TR, Khudyakov Y, Annambhotla PD, Basavaraju SV, Kamili S, Ritter JM, et al. 2017. Transmission of hepatitis A virus through combined liver-small intestine-pancreas transplantation. Emerg Infect Dis 23: 590-596.

Garaigorta U, Chisari FV. 2009. Hepatitis C virus blocks interferon effector function by inducing protein kinase R phosphorylation. Cell Host Microbe 6: 513-522.

Garcia MA, Gil J, Ventoso I, Guerra S, Domingo E, Rivas C, Esteban M. 2006. Impact of protein kinase PKR in cell biology: From antiviral to antiproliferative action. Microbiol Mol Biol Rev 70: 1032-1060.

Ge D, Fellay J, Thompson AJ, Simon JS, Shianna KV, Urban TJ, Heinzen EL, Qiu P, Bertelsen AH, Muir AJ, et al. 2009. Genetic variation in IL28B predicts hepatitis C treatmentinduced viral clearance. Nature 461: 399-401.

Golden-Mason L, Rosen HR. 2013. Natural killer cells: Multifaceted players with key roles in hepatitis $\mathrm{C}$ immunity. Immunol Rev 255: 68-81.

Grandvaux N, Servant MJ, tenOever B, Sen GC, Balachandran S, Barber GN, Lin R, Hiscott J. 2002. Transcriptional profiling of interferon regulatory factor 3 target genes: Direct involvement in the regulation of interferon-stimulated genes. J Virol 76: 5532-5539.
Guo H, Callaway JB, Ting JP. 2015. Inflammasomes: Mechanism of action, role in disease, and therapeutics. Nat Med 21: 677-687.

He M, Wang M, Huang Y, Peng W, Zheng Z, Xia N, Xu J, Tian D. 2016. The ORF3 protein of genotype 1 hepatitis $\mathrm{E}$ virus suppresses TLR3-induced NF- $\mathrm{KB}$ signaling via TRADD and RIP1. Sci Rep 6: 27597.

Helsen N, Debing Y, Paeshuyse J, Dallmeier K, Boon R, Coll M, Sancho-Bru P, Claes C, Neyts J, Verfaillie CM. 2016. Stem cell-derived hepatocytes: A novel model for hepatitis E virus replication. J Hepatol 64: 565-573.

Hermant P, Demarez C, Mahlakoiv T, Staeheli P, Meuleman P, Michiels T. 2014. Human but not mouse hepatocytes respond to interferon- $\lambda$ in vivo. PLoS ONE 9: e87906.

Hirai-Yuki A, Hensley L, McGivern DR, Gonzalez-Lopez O, Das A, Feng H, Sun L, Wilson JE, Hu F, Feng Z, et al. 2016a. MAVS-dependent host species range and pathogenicity of human hepatitis A virus. Science 15: aaf8325.

Hirai-Yuki A, Hensley L, Whitmire JK, Lemon SM. 2016b. Biliary secretion of quasi-enveloped human hepatitis A virus. MBio 7: $\mathrm{e} 01998$.

* Hirai-Yuki A, Whitmire JK, Joyce M, Tyrrell DL, Lemon SM. 2018. Murine models of hepatitis A virus infection. Cold Spring Harb Perspect Med doi: 10.1101/cshperspect. a031674.

Hocini H, Bomsel M. 1999. Infectious human immunodeficiency virus can rapidly penetrate a tight human epithelial barrier by transcytosis in a process impaired by mucosal immunoglobulins. J Infect Dis 179: S448-S453.

Horner SM, Gale M Jr, 2013. Regulation of hepatic innate immunity by hepatitis C virus. Nat Med 19: 879-888.

Jha S, Ting JPY. 2015. Holding the inflammatory system in check: NLRs keep it cool. F1000Prime Rep 7: 15.

* Kamar N, Pischke S. 2018. Acute and persistent hepatitis E virus genotype 3 and 4 infections: Clinical features, pathogenesis, and treatment. Cold Spring Harb Perspect Med doi: 10.1101/cshperspect.a031872.

Karpe YA, Lole KS. 2011. Deubiquitination activity associated with hepatitis $\mathrm{E}$ virus putative papain-like cysteine protease. J Gen Virol 92: 2088-2092.

* Kenney SP, Meng X-J. 2018. Hepatitis E virus genome structure and replication strategy. Cold Spring Harb Perspect Med doi: 10.1101/cshperspect.a031724.

Khan M, Syed GH, Kim SJ, Siddiqui A. 2016. Hepatitis B virus-induced parkin-dependent recruitment of linear ubiquitin assembly complex (LUBAC) to mitochondria and attenuation of innate immunity. PLoS Pathog 12: e1005693.

Lanford RE, Feng Z, Chavez D, Guerra B, Brasky KM, Zhou Y, Yamane D, Perelson AS, Walker CM, Lemon SM. 2011 Acute hepatitis A virus infection is associated with a limited type I interferon response and persistence of intrahepatic viral RNA. Proc Natl Acad Sci 108: 11223-11228.

* Lanford RE, Walker CM, Lemon SM. 2018. Nonhuman primate models of hepatitis A virus and hepatitis E virus infections. Cold Spring Harb Perspect Med doi: 10.1101/ cshperspect.a031815.

Lemon SM. 2010. Induction and evasion of innate antiviral responses by hepatitis C virus. J Biol Chem 285: 2274122747. 
Li K, Chen Z, Kato N, Gale M Jr, Lemon SM. 2005. Distinct poly-I:C and virus-activated interferon signaling pathways in hepatocytes. J Biol Chem 280: 16739-16747.

Mathiesen LR, Moller AM, Purcell RH, London WT, Feinstone SM. 1980. Hepatitis A virus in the liver and intestine of marmosets after oral inoculation. Infect Immun 28: $45-48$.

* McKnight KL, Lemon SM. 2018. Hepatitis A virus genome organization and replication strategy. Cold Spring Harb Perspect Med doi: 10.1101/cshperspect.a033480.

Moal V, Textoris J, Ben Amara A, Mehraj V, Berland Y, Colson P, Mege JL. 2013. Chronic hepatitis E virus infection is specifically associated with an interferon-related transcriptional program. J Infect Dis 207: 125-132.

Myong S, Cui S, Cornish PV, Kirchhofer A, Gack MU, Jung JU, Hopfner KP, Ha T. 2009. Cytosolic viral sensor RIG-I is a $5^{\prime}$-triphosphate-dependent translocase on doublestranded RNA. Science 323: 1070-1074.

Nan Y, Ma Z, Wang R, Yu Y, Kannan H, Fredericksen B, Zhang YJ. 2014a. Enhancement of interferon induction by ORF3 product of hepatitis E virus. J Virol 88: 86968705.

Nan Y, Yu Y, Ma Z, Khattar SK, Fredericksen B, Zhang YJ. 2014b. Hepatitis E virus inhibits type I interferon induction by ORF1 products. J Virol 88: 11924-11932.

Negash AA, Ramos HJ, Crochet N, Lau DT, Doehle B, Papic N, Delker DA, Jo J, Bertoletti A, Hagedorn CH, et al. 2013. IL- $1 \beta$ production through the NLRP 3 inflammasome by hepatic macrophages links hepatitis $C$ virus infection with liver inflammation and disease. PLoS Pathog 9: e1003330.

* Nelson KE, Labrique AB, Kmush BL. 2018. Epidemiology of genotype 1 and 2 hepatitis E virus infections. Cold Spring Harb Perspect Med doi: 10.1101/cshperspect.a031732.

Nice TJ, Baldridge MT, McCune BT, Norman JM, Lazear HM, Artyomov M, Diamond MS, Virgin HW. 2015. Interferon- $\lambda$ cures persistent murine norovirus infection in the absence of adaptive immunity. Science 347: 269-273.

Ouzilou L, Caliot E, Pelletier I, Prevost MC, Pringault E, Colbere-Garapin F. 2002. Poliovirus transcytosis through M-like cells. J Gen Virol 83: 2177-2182.

Pandey S, Kawai T, Akira S. 2014. Microbial sensing by Tolllike receptors and intracellular nucleic acid sensors. Cold Spring Harb Perspect Biol 7: a016246.

Peterson LW, Artis D. 2014. Intestinal epithelial cells: Regulators of barrier function and immune homeostasis. Nat Rev Immunol 14: 141-153.

Petrasek J, Iracheta-Vellve A, Csak T, Satishchandran A, Kodys K, Kurt-Jones EA, Fitzgerald KA, Szabo G. 2013. STING-IRF3 pathway links endoplasmic reticulum stress with hepatocyte apoptosis in early alcoholic liver disease. Proc Natl Acad Sci 110: 16544-16549.

* Pintó RM, Pérez-Rodríguez F-J, D’Andrea L, de Castellarnau M, Guix S, Bosch A. 2018. Hepatitis A virus codon usage: Implications for translation kinetics and capsid folding. Cold Spring Harb Perspect Med doi: 10.1101/cshperspect. a031781.

Pott J, Mahlakoiv T, Mordstein M, Duerr CU, Michiels T, Stockinger S, Staeheli P, Hornef MW. 2011. IFN- $\lambda$ determines the intestinal epithelial antiviral host defense. Proc Natl Acad Sci 108: 7944-7949.
Innate Immunity to Enteric Hepatitis Viruses

Prokunina-Olsson L, Muchmore B, Tang W, Pfeiffer RM, Park H, Dickensheets H, Hergott D, Porter-Gill P, Mumy A, Kohaar I, et al. 2013. A variant upstream of IFNL3 (IL28B) creating a new interferon gene IFNL4 is associated with impaired clearance of hepatitis C virus. Nat Genet 45: 164-171.

Purcell RH, Wong DC, Shapiro M. 2002. Relative infectivity of hepatitis A virus by the oral and intravenous routes in 2 species of nonhuman primates. J Infect Dis 185: 1668 1671.

Purcell RH, Engle RE, Govindarajan S, Herbert R, St Claire M, Elkins WR, Cook A, Shaver C, Beauregard M, Swerczek J, et al. 2013. Pathobiology of hepatitis E: Lessons learned from primate models. Emerg Microbes Infect 2: e9.

Qu L, Lemon SM. 2010. Hepatitis A and hepatitis C viruses: Divergent infection outcomes marked by similarities in induction and evasion of interferon responses. Semin Liver Dis 30: 319-332.

Qu L, Feng Z, Yamane D, Liang Y, Lanford RE, Li K, Lemon SM. 2011. Disruption of TLR3 signaling because of cleavage of TRIF by the hepatitis A virus protease-polymerase processing intermediate, 3CD. PLoS Pathog 7: e1002169.

Rajan JV, Rodriguez D, Miao EA, Aderem A. 2011. The NLRP3 inflammasome detects encephalomyocarditis virus and vesicular stomatitis virus infection. J Virol 85: 4167-4172.

Reich NC. 2013. A death-promoting role for ISG54/IFIT2. J Interferon Cytokine Res 33: 199-205.

Rosenblum LS, Villarino ME, Nainan OV, Melish ME, Hadler SC, Pinsky PP, Jarvis WR, Ott CE, Margolis HS. 1991. Hepatitis A outbreak in a neonatal intensive care unit: Risk factors for transmission and evidence of prolonged viral excretion among preterm infants. J Infect Dis 164: 476-482.

* Sander A-L, Corman VM, Lukashev AN, Drexler JF. 2018. Evolutionary origins of enteric hepatitis viruses. Cold Spring Harb Perspect Med doi: 10.1101/cshperspect. a031690.

Sarasin-Filipowicz M, Wang X, Yan M, Duong FH, Poli V, Hilton DJ, Zhang DE, Heim MH. 2009. $\alpha$ Interferon induces long-lasting refractoriness of JAK-STAT signaling in the mouse liver through induction of USP18/ UBP43. Mol Cell Biol 29: 4841-4851.

Sato S, Li K, Kameyama T, Hayashi T, Ishida Y, Murakami S, Watanabe T, Iijima S, Sakurai Y, Watashi K, et al. 2015. The RNA sensor RIG-I dually functions as an innate sensor and direct antiviral factor for hepatitis B virus. Immunity 42: 123-132.

Sayed IM, Verhoye L, Cocquerel L, Abravanel F, Foquet L, Montpellier C, Debing Y, Farhoudi A, Wychowski C, Dubuisson J, et al. 2016. Study of hepatitis E virus infection of genotype 1 and 3 in mice with humanised liver. Gut 66: 920-929.

Schlee M, Roth A, Hornung V, Hagmann CA, Wimmenauer V, Barchet W, Coch C, Janke M, Mihailovic A, Wardle G, et al. 2009. Recognition of $5^{\prime}$ triphosphate by RIG-I helicase requires short blunt double-stranded RNA as contained in panhandle of negative-strand virus. Immunity 31: $25-34$. 
Schoggins JW, Rice CM. 2011. Interferon-stimulated genes and their antiviral effector functions. Curr Opin Virol 1: 519-525.

Schulman AN, Dienstag JL, Jackson DR, Hoofnagle JH, Gerety RJ, Purcell RH, Barker LF. 1976. Hepatitis A antigen particles in liver, bile, and stool of chimpanzees. J Infect Dis 134: 80-84.

Sheahan T, Imanaka N, Marukian S, Dorner M, Liu P, Ploss A, Rice CM. 2014. Interferon $\lambda$ alleles predict innate antiviral immune responses and hepatitis $C$ virus permissiveness. Cell Host Microbe 15: 190-202.

* Shin E-C, Jeong S-H. 2018. Natural history, clinical manifestations, and pathogenesis of hepatitis A. Cold Spring Harb Perspect Med doi: 10.1101/cshperspect.a031708.

Stawowczyk M, Van Scoy S, Kumar KP, Reich NC. 2011. The interferon stimulated gene 54 promotes apoptosis. J Biol Chem 286: 7257-7266.

Su AI, Pezacki JP, Wodicka L, Brideau AD, Supekova L, Thimme R, Wieland S, Bukh J, Purcell RH, Schultz PG, et al. 2002. Genomic analysis of the host response to hepatitis C virus infection. Proc Natl Acad Sci 99: 15669-15674.

Sung PS, Hong SH, Lee J, Park SH, Yoon SK, Chung WJ, Shin EC. 2017. CXCL10 is produced in hepatitis A virusinfected cells in an IRF3-dependent but IFN-independent manner. Sci Rep 7: 6387.

Surjit M, Varshney B, Lal SK. 2012. The ORF2 glycoprotein of hepatitis E virus inhibits cellular NF- $\mathrm{KB}$ activity by blocking ubiquitination mediated proteasomal degradation of IKB $\alpha$ in human hepatoma cells. BMC Biochem 13: 7.

Swiecki M, Colonna M. 2015. The multifaceted biology of plasmacytoid dendritic cells. Nat Rev Immunol 15: 471485.

Taylor PE, Zuckerman AJ. 1968. Lack of production of interfering substances in infectious hepatitis. J Clin Pathol 21: 794.

Thomas DL, Thio CL, Martin MP, Qi Y, Ge D, O'Huigin C, Kidd J, Kidd K, Khakoo SI, Alexander G, et al. 2009. Genetic variation in IL28B and spontaneous clearance of hepatitis C virus. Nature 461: 798-801.

Todt D, Francois C, Anggakusuma, Behrendt P, Engelmann M, Knegendorf L, Vieyres G, Wedemeyer H, Hartmann R, Pietschmann T, et al. 2016. Antiviral activities of different interferon types and subtypes against hepatitis $\mathrm{E}$ virus replication. Antimicrob Agents Chemother 60: 21322139.
Vallbracht A, Hofmann L, Wurster KG, Flehmig B. 1984. Persistent infection of human fibroblasts by hepatitis A virus. J Gen Virol 65: 609-615.

van de Garde MDB, Pas SD, van Oord GW, Gama L, Choi Y, de Man RA, Boonstra A, Vanwolleghem T. 2017. Interferon- $\alpha$ treatment rapidly clears hepatitis $\mathrm{E}$ virus infection in humanized mice. Sci Rep 7: 8267.

Wang D, Fang L, Wei D, Zhang H, Luo R, Chen H, Li K, Xiao S. 2014. Hepatitis A virus $3 \mathrm{C}$ protease cleaves NEMO to impair induction of $\beta$ interferon. J Virol 88: 10252-10258.

Wang W, Xu L, Brandsma JH, Wang Y, Hakim MS, Zhou X, Yin Y, Fuhler GM, van der Laan LJ, van der Woude CJ, et al. 2016. Convergent transcription of interferon-stimulated genes by TNF- $\alpha$ and IFN- $\alpha$ augments antiviral activity against HCV and HEV. Sci Rep 6: 25482.

Weitz M, Baroudy BM, Maloy WL, Ticehurst JR, Purcell RH. 1986. Detection of a genome-linked protein (VPg) of hepatitis A virus and its comparison with other picornaviral VPgs. J Virol 60: 124-130.

Wen H, Miao EA, Ting JP. 2013. Mechanisms of NOD-like receptor-associated inflammasome activation. Immunity 39: 432-441.

Wheelock EF, Schenker S, Combes B. 1968. Absence of circulating interferon in patients with infectious and serum hepatitis. Proc Soc Exp Biol Med 128: 251-253.

Yang Y, Liang Y, Qu L, Chen Z, Yi M, Li K, Lemon SM. 2007. Disruption of innate immunity due to mitochondrial targeting of a picornaviral protease precursor. Proc Natl Acad Sci 104: 7253-7258.

Yin X, Li X, Feng Z. 2016. Role of envelopment in the HEV life cycle. Viruses 8: E229.

Yin X, Li X, Ambardekar C, Hu Z, Lhomme S, Feng Z. 2017. Hepatitis $\mathrm{E}$ virus persists in the presence of a type III interferon response. PLoS Pathog 13: e1006417.

Yu C, Boon D, McDonald SL, Myers TG, Tomioka K, Nguyen H, Engle RE, Govindarajan S, Emerson SU, Purcell RH. 2010. Pathogenesis of hepatitis E virus and hepatitis $C$ virus in chimpanzees: Similarities and differences. J Virol 84: 11264-11278.

Zhang F, Qi Y, Harrison TJ, Luo B, Zhou Y, Li X, Song A, Huang W, Wang Y. 2014. Hepatitis E genotype 4 virus from feces of monkeys infected experimentally can be cultured in PLC/PRF/5 cells and upregulate host interferon-inducible genes. J Med Virol 86: 1736-1744.

Zhou Y, Callendret B, Xu D, Brasky KM, Feng Z, Hensley LL, Guedj J, Perelson AS, Lemon SM, Lanford RE, et al. 2012. Dominance of the $\mathrm{CD} 4^{+} \mathrm{T}$ helper cell response during acute resolving hepatitis A virus infection. J Exp Med 209: 1481-1492. 


\section{$\&_{\mathrm{CSH}}^{\infty} \&$ Cold Spring Harbor

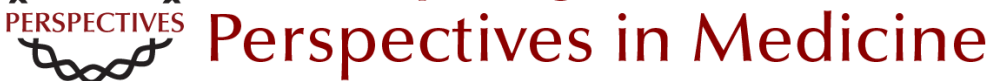

\section{Innate Immunity to Enteric Hepatitis Viruses}

Zongdi Feng and Stanley M. Lemon

Cold Spring Harb Perspect Med 2019; doi: 10.1101/cshperspect.a033464 originally published online April 23, 2018

\section{Subject Collection Enteric Hepatitis Viruses}

Hepatitis A Virus Genome Organization and Replication Strategy

Kevin L. McKnight and Stanley M. Lemon

Adaptive Immune Responses in Hepatitis A Virus and Hepatitis E Virus Infections

Christopher M. Walker

Small Animal Models of Hepatitis E Virus Infection Tian-Cheng Li and Takaji Wakita

Acute and Persistent Hepatitis E Virus Genotype 3 and 4 Infection: Clinical Features, Pathogenesis, and Treatment Nassim Kamar and Sven Pischke

Epidemiology of Genotype 1 and 2 Hepatitis E Virus Infections

Kenrad E. Nelson, Alain B. Labrique and Brittany L. Kmush

History of the Discovery of Hepatitis A Virus Stephen M. Feinstone

Epidemiology and Transmission of Hepatitis A Virus and Hepatitis E Virus Infections in the United States

Megan G. Hofmeister, Monique A. Foster and Eyasu H. Teshale

Stem Cell-Derived Culture Models of Hepatitis E Virus Infection

Viet Loan Dao Thi, Xianfang Wu and Charles M. Rice
Evolutionary Origins of Enteric Hepatitis Viruses Anna-Lena Sander, Victor Max Corman, Alexander N. Lukashev, et al.

Enterically Transmitted Non-A, Non-B Hepatitis and the Discovery of Hepatitis E Virus

Stanley M. Lemon and Christopher M. Walker

Natural History, Clinical Manifestations, and

Pathogenesis of Hepatitis E Virus Genotype 1 and

2 Infections

Rakesh Aggarwal and Amit Goel

Hepatitis A Virus and Hepatitis E Virus: Emerging and Re-Emerging Enterically Transmitted

Hepatitis Viruses

Stanley M. Lemon and Christopher M. Walker

Hepatitis A Virus Capsid Structure

David I. Stuart, Jingshan Ren, Xiangxi Wang, et al.

Comparative Pathology of Hepatitis A Virus and Hepatitis E Virus Infection John M. Cullen and Stanley M. Lemon

Innate Immunity to Enteric Hepatitis Viruses Zongdi Feng and Stanley M. Lemon

Nonhuman Primate Models of Hepatitis A Virus and Hepatitis E Virus Infections

Robert E. Lanford, Christopher M. Walker and

Stanley M. Lemon

For additional articles in this collection, see http://perspectivesinmedicine.cshlp.org/cgi/collection/ 